\title{
XENOFOBIA Y DISCRIMINACIÓN
}

Sara Ulloa Aiza

\section{Algunos factores históricos}

El problema de la xenofobia o bien de la intolerancia hacia personas de otras naciones, razas o grupos étnicos distintos al propio, ha sido parte de la Historia desde civilizaciones ancestrales y con frecuencia ha estado latente en relaciones y luchas por el poder económico.

La xenofobia ha servido muchas veces de pretexto para someter a pueblos arguyendo razones religiosas, culturales, raciales, etc. Y es así, como el ser humano ha permitido que a través de la exaltación del odio, se cometan atrocidades a sus congéneres. La construcción de las asombrosas pirámides en Egipto, usando a grupos considerados inferiores, podrían ser un buen ejemplo sobre la práctica de la esclavitud, asociada al xenofobismo y la discriminación. 
Es también el caso del Imperio Romano que dominó y expolió por miles de años a pueblos de Europa, el Asia Menor, África y Oriente Próximo. El imperio Otomano, repite en mayor o menor medida la misma táctica de conquista e igual sometimiento en cobro de impuestos, que permitió la constitución de grandes imperios a costa del sufrimiento de otros pueblos. Parte de esa Historia la constituye también las cruzadas cristianas, la expulsión de los judíos y musulmanes de España. Y las incursiones de Castilla en Marruecos en el siglo XV, practicando "la ratería," la cual enriqueció a muchos cristianos, les aportó extensiones territoriales y mano de obra semi-servil morisca. ${ }^{1}$

Un modelo característico de luchas de poder, fue el utilizado para ir desplazando a los Turcos-Otomanos; los franceses se aliaron a los maronitas cristianos en el Líbano; Gran Bretaña para obtener más poder tuvo mayor acercamiento a los druzos; en Palestina, los Británicos se hicieron defensores de los Judíos, todas estas protecciones han sido un medio más de penetración y expansión económica. ${ }^{2}$

Las luchas religiosas en el Medio Oriente también han contado en épocas recientes, con el apoyo de los países económicamente poderosos en virtud de sus propios intereses, que varían conforme a las condiciones históricas que experimentan. Además comprueban que la especie humana ha usado su propia crueldad en contra de sus semejantes, destacando para ello aparentes diferencias raciales, religiosas,

\footnotetext{
1. Hernández Omar, Ibarra Eugenia, Quesada Juan. Discriminación y Racismo, en la Historia Costarricense, San José Editorial Universidad de Costa Rica 1993, pág. 38.

2. Para profundizar en el tema leer Maalouf Amín. La cruzadas vistas por los árabes e Identidades Asesinas, Madrid, Edit. Cast,: Alianza editorial S.A. además Marín Guzmán Roberto. La Emigración Libanesa en los Siglos XIX y XX: análisis de sus causas sociales y económicas, San José Edt. Alma Mater, 1977.
} 
culturales o históricas que en realidad procuran el beneficio de unos pocos. Las metrópolis del poder justifican su proceder asumiendo la misma postura griega con la "polis", en el sentido de que su misión es vigilar y educar a colectividades sobre las que asumen una cultura y comportamiento inferior o bárbaro. Inclusive se aducen criterios genéticos en la justificación de su actitud. Por otra parte la religión basada en los libros sagrados va a legitimar la invasión de territorios.

\section{América Latina}

En los albores de la época moderna el llamado "Descubrimiento de América" marcó pautas que pretendieron justificar una violenta discriminación y violación de los derechos de las personas. Esto es típico no sólo en épocas coloniales sino en los tiempos actuales, bajo el mismo modelo de dominación. "Descubrir" es una falacia que hoy día es absolutamente clara. La razón de ser -de ese descubrir- era justificar el saqueo de las riquezas que poseían los pueblos a ser conquistados. El holocausto indígena refleja bien la "calidad humanista" y la ausencia de conceptos éticos y morales del naciente capitalismo mundial; conceptos que en la actualidad no alcanzan contenido, a pesar de que se usan con facilidad en diferentes foros e instancias nacionales e internacionales.

Diversos historiadores apuntan que los problemas de unificación y desigualdades actuales tienen sus raíces en la colonia. Las diferencias fueron artificialmente construidas para "mantener en su lugar" al indígena, al negro y al resto de las castas que eran producto de las mezclas raciales. El eurocentrismo que toma lugar a partir del Siglo XVI tiene un importante impacto en la población americana hasta el día de hoy. En este sentido existen sectores sociales que 
destacan con jactancia excesiva su ascendencia europea. Irónicamente, los primeros pobladores del continente, los pocos que lograron sobrevivir a la explotación y a la violencia, continúan como los "otros" los extraños, arrinconados, víctimas de la explotación. A pesar de esta realidad se responsabiliza todavía hoy en día al indígena, por el "atraso y el oscurantismo". Incluso se dice que no se puede salir del subdesarrollo, debido a la composición de la población. ${ }^{3}$

\subsection{Un caso: Guatemala}

Un ejemplo representativo de lo que sucede en el resto de América, es el caso de Guatemala, donde la mayoría de su población es indígena. Sin embargo sus derechos fundamentales, son violados sistemáticamente, por dirigentes políticos y empresarios locales con apoyo algunas veces de intereses económicos externos. Se han arrasado pueblos enteros para la explotación de sus recursos naturales (petróleo, minería y madera, son algunos ejemplos).

Noan Chomsky basándose en un artículo aparecido en el New York Times hace la siguiente acotación:

"A medida que las matanzas indígenas por parte de militares guatemaltecos se fueron aproximando a un genocidio, Ronald Reagan y sus funcionarios al tiempo que alababan a los asesinos defendiéndolos como demócratas progresistas, informaban al Congreso que proporcionaría armas

3. Op. Ci.t, pp.61-75

En días recientes en una entrevista de televisión (entrevista Pilar Cisneros en la tercera edición de Telenoticias canal 7) el candidato a presidente Ottón Solís hacía énfasis en que -si queremos terminar con nuestros problemas actuemos como europeos y no como latinoamercanos- la misma posición es adoptada por escritores que dicen ser latinoamericanistas y abierta o solapadamente esgrimen el mismo argumento. 
para reforzar la mejora de la situación de los derechos $h u$ manos - tras el golpe de 1982-que instauró al General Ríos Montt, quizá el mayor asesino de todos." 4

\section{Prácticas colonialistas y xenofobia}

Similar práctica colonialista asumieron los ingleses en sus colonias y también presentan éstas, los mismos problemas estructurales. Pablo Neruda, nos describe sus vivencias como diplomático en la India cuando estaba en manos inglesas:

"En la India no había en aquellos años muchos sitios para las contemplaciones del ombligo profundo. Una vida de brutales exigencias materiales, una condición colonial cimentada en la más acendrada abyección, miles de muertos cada día, cólera, viruela, de fiebres, hambre. Organizaciones feudales desequilibradas por su inmensa población y su pobreza industrial, imprimian a la vida una ferocidad en la que los espejos míticos desaparecían". 5

Además Chomsky, basado en sus estudios al respecto, contribuye a establecer un claro escenario de la situación de la India a mediados del siglo XVIII describiendo, cómo este país estaba comparativamente desarrollado en varios sectores tales como el textil, astilleros, metalurgia, el vidrio, etc. y fue la colonización inglesa la culpable del estancamiento de estas áreas, para inducir a este país en la agricultura. ${ }^{6}$

\footnotetext{
4. Chomsky Noam, Año 501 . La Conquista Continua. España Edit. Libertarias Prodhufi, S.A., 1993, pág. 43.

5. Neruda Pablo, Confieso que he Vivido. Memorias. Edit. Seix Borral, S.A España 1979. pág. 120.

6. Op. Cit., pág. 24.
} 
También debe recordarse la cruel colonización de los belgas en el Congo, la de los ingleses en Irlanda y en Sud África con la discriminación institucionalizada (Apartheid) durante décadas y que culmina con la liberación del líder negro Nelson Mandela.

La llegada al poder en 1932 del Partido Nacional Socialista en Alemania; es el ejemplo más importante de la historia contemporánea y más demostrativo del peligro de exaltar los odios y de cómo estos odios son caldo de cultivo en los momentos de crisis económicas y sociales. Esta situación provoca el desenlace de la II Guerra Mundial; en la cual se perdieron millares de vidas en los campos de batalla, en los campos de concentración y en el bombardeo en el cual el "Enola gay" dispara la letal carga atómica sobre las poblaciones de Hiroshima y Nagasaky.

\section{Naciones Unidas. Discriminación y minorías. Gé- nesis}

La continuación de los problemas de intolerancia, incentiva la creación en 1957 de una subcomisión en el seno de la Asamblea general de la Organización de Naciones Unidas, sobre "Prevención de Discriminación y Protección de Las Minorías," este es el punto de partida para los futuros estudios en discriminación. El informe rendido por esta comisión a finales de los años 1960, hace énfasis en la educación como pilar fundamental para la tolerancia y a su vez amplía el concepto de derechos de libertad de pensamiento, conciencia o religión y más tarde se añade el de convicción teísta, no teísta y atea. ${ }^{7}$

7. Odio Elizabeth. Eliminación de todas las formas de intolerancia y discriminación fundadas en la religión o las convicciones. Nueva York, Publicación de la ONU, 1989. 
Esta preocupación de aceptación tanto de raza como de religión está presente, hoy en el escenario mundial con más ímpetu, ya que a mediados de siglo $\mathrm{XX}$ recrudecieron las guerras y continúan azuzándose las primitivas disputas que se enmascaran en un delirio étnico-religioso, que en el fondo son parte también de intereses de poder político y económico.

\section{Segunda mitad del Siglo XX. Otros ejemplos}

En Afganistán los talibanes, grupo islámico fundamentalista en el poder, emplea el fanatismo religioso para llevar a cabo su ideario. Víctima importante de su intolerancia y de su delirio machista es la mujer, a quien le imponen reglas inhumanas y atroces. Estos extremistas hace pocos meses emulando a los inquisidores cristianos, cometieron el sacrilegio de tumbar sin ningún miramiento, milenarias estatuas de Buda, que eran patrimonio de la humanidad. Este grupo ha obtenido la condena de la comunidad internacional y se han convertido en un clásico peligro de intolerancia xenofóbica a todo aquello considerado "infiel".

Otro ejemplo de actualidad lo constituye el conflicto israelí-palestino, en el cual con frecuencia se pasa por alto, las barbaries cometidas. Ya que se actúa de conformidad con los intereses imperantes en el ámbito internacional.

Muestra de lo anterior son las prácticas terroristas. Se ponen bombas en los autobuses, en centros comerciales, se destruyen barrios enteros en bombardeos indiscriminados y "selectivos". Concomitantemente se manifiesta la intolerancia al confinar poblaciones, impedir el libre tránsito de personas y continuar construyendo asentamientos en territorios que reclaman ambas partes. En fin cada parte asume fanáticamente su verdad. 
En la Europa del Este tanto los albaneses, como los yugoslavos, los polacos, los checoslovacos entre otros, luchan para lograr una inserción en el mercado mundial que permita a sus habitantes, no tener que emigrar, pues, tanto los gobernantes como la población de Europa Occidental dan señales permanentes de no querer admitirlos en sus países.

El caso de la antigua Yugoslavia, la problemática entre croatas, bosnios, serbios y montenegrinos, quienes se niegan a seguir unidos, han puesto en boga de nuevo el significado a la palabra "balcanición," un conflicto de etnias, religiones e intereses político-económicos que hace recordar los campos de concentración utilizados en la Segunda Guerra Mundial, (sólo que ahora las víctimas son musulmanes.) No obstante pasó mucho tiempo para que la comunidad internacional se interesara. Antes murieron, se torturaron, se exterminaron a miles de personas inocentes y el sufrimiento aún continúa. Esta ola de violencia y odio no se detuvo a tiempo, por no afectar intereses de naciones poderosas. Por mucho menos se invadió Irak o Grenada.

\section{La crisis en su dimensión actual. Efectos de la glo- balización}

Como expusimos anteriormente, la lucha librada, tanto en el medio jurídico, como de educación en las personas, no han sido hasta el momento suficiente para combatir el creciente etnocentrismo en el mundo y por el contrario la crisis económica en la actualidad está agudizando el problema.

El mayor inconveniente, lo proporciona el fenómeno globalizador en los medios de comunicación, lo que lleva a que la crisis económica (en menor o mayor grado) impacto con mayor celeridad a los diferentes países que componen la 
"Aldea Global". El desarrollo vertiginoso de las comunicaciones, a su vez acelera la velocidad con la que se expandan la violencia y el rencor, que se anida entre pequeños grupos xenofóbicos los cuales rápidamente se comunican y se identifican de un sitio a otro en el ámbito internacional.

La globalización ha variado el carácter, la frecuencia y el grado de complejidad de las interacciones entre ese tipo de grupos, a pesar de la voluntad de los actores que se les oponen en la comunidad internacional.

En el período post-bélico, el hombre logró una aparente armonía y un desarrollo tecnológico que le ayudó a alcanzar avances en el aumento de los niveles de riqueza, como nunca antes lo había tenido. Sin embargo, esta bonanza careció de equidad en la distribución de los beneficios, lo cual se evidenció tanto en el interior de los países como en sus relaciones internacionales. La dimensión de este problema se visualiza mejor si se toma en cuenta que en la actualidad la población mundial se concentra en un $85 \%$ en los países periféricos y tan solo un $15 \%$ en los países del centro.

El esquema de desarrollo liberal que se implantó en los años ochenta, (aunque excluyente por naturaleza, lo fue aún más con los países ya de por sí empobrecidos) profundizó las diferencias tanto dentro de los países, como entre éstos y otros estados.

Así por ejemplo diferentes analistas tales como Morgan, o algunos representantes del Banco Mundial como Lewis Preston, han hecho énfasis reiteradamente en la hipocresía de las naciones económicamente poderosas, cuando exigen mercados abiertos a los países pobres y al mismo tiempo su 
práctica es proteccionista sobre todo a la entrada de los productos provenientes de los países del sur. Asimismo subrayan que dichas medidas, reducen al doble la cantidad que estas naciones les brindan como ayuda oficial. ${ }^{8}$

Los países de la periferia deben manejar problemas, tales como el acelerado crecimiento de su población y la adquisición de una paupérrima porción de la riqueza mundial. Agravan su situación en virtud de la pésima distribución interna de sus escasos recursos (el $40 \%$ de su población percibe tan sólo el $9 \%$ del total de sus ingresos) la carencia de tecnología y el analfabetismo entre otros. Por su parte el centro vive en la opulencia e impone a otros sacrificios que implican problemas mayores mientras continúa la explotación sistemática de la riqueza.

De acuerdo con esta lógica de extracción tenemos que los países de mayor desarrollo consumen el $70 \%$ de la energía mundial, el $75 \%$ de los metales, el $85 \%$ de la madera y el $60 \%$ de los alimentos. Además las grandes diferencias en el acceso a los servicios, hacen que la injusticia se incremente día a día. Los países en desarrollo paradójicamente tienen una participación en el comercio mundial de un $19 \%$ mientras los desarrollados dominan el $80 \%$ de éste.

En el caso de América Latina su participación en el comercio internacional disminuyó en 20 años de un $5.6 \%$ a un $3.6 \%$. En cuanto al acceso a los préstamos de la banca comercial internacional, apenas tiene acceso a un $0.2 \%$ de los mismos ${ }^{9}$.

\footnotetext{
8. Chomsky Noam, Op. Cit., pág., 89.

9. Para el estudio de los "efectos de la globalización" consultar los informes al respecto de Comisión Económica para América Latina, y del Programa de Naciones Unidas para el Desarrollo.
} 
Toda esta compleja situación política, social y económica es lo que hace que se incrementen los desplazamientos de seres humanos de un lugar a otro fomentando la problemática de las migraciones. El desplazamiento se da por razones diversas tales como escapar a los problemas políticos, a las persecuciones étnicas, las raciales, las religiosas o bien por desempleo en virtud de la crisis económica que afecta a unos países más que a otros.

Es duro además admitir que la esperanza albergada hace pocos años de que los países menos desarrollados serían forzosamente necesarios por la mano de obra y las materias primas, se desvanece cada vez más en virtud a la sofisticación tecnológica alcanzada, que no sólo permite sustituir a las personas, sino también a la materia prima que antes era indispensable importar del sur. Por ello las inversiones de las transnacionales tienden a su vez a concentrarse en el ámbito de los países industrializados y tan solo un $0.2 \%$ se produce en los países subdesarrollados. Lo enunciado permite tener una comprensión global acerca del aumento del éxodo de millones de seres humanos, que van buscando mejores oportunidades para sus familias, en aquellos países que desde su prisma personal, van a constituir la diferencia entre la vida sin violencia y con alimento. En este momento la comunidad internacional está pasando por problemas similares y el embate es más intenso, dependiendo de la vulnerabilidad de cada país. Y en ello los países más vulnerables siempre van a ser los más pobres, aunque como bien lo apunta Nohan Chomsky, los países ricos están adoptando en la actualidad en su interior "un aspecto un tanto tercermundista", con islotes de extrema riqueza y privilegio, frente a un grupo creciente de población en medio de la pobreza y desesperación. ${ }^{10}$

10. Ibíd, pág. 85 
Europa Occidental presenta problemas de lento crecimiento económico, (del 1994 hasta el 2000 ha crecido en promedio $1,5 \%$ por año) y obviamente el desempleo no decrece. Contrariamente en países como Alemania tiende al alza. En este momento existe la preocupación y la discusión entre los que sostienen que deben realizarse mayores esfuetzos para reducir el empleo, como la Comunidad Económica Europea(CEE); y los que aducen que al tratar de aumentar el empleo forzadamente, puede haber un aumento de la inflación. La Comunidad Económica Europea, alega que el no hacerlo representa terminar con la estabilidad, pues diariamente se está incubando en una parte importante de la población, la desilusión, la frustración y la exclusión; y por supuesto hay otra preocupación que no menciona el artículo, pero que se está incrementado rápidamente en Europa occidental, es el odio hacia el "otro" con manifestaciones y persecuciones raciales latentes que incluso han llevado en Alemania a incinerar familias turcas.

Por otra parte en Estados Unidos, se están cerrando grandes empresas, por la crisis económica y se maneja una cifra de desempleo de un $4.5 \%$, la misma crisis económica la está viviendo Japón en la actualidad. ${ }^{11}$

\section{América Latina y actitudes xenofóbicas actuales}

Esta problemática política y económica, de los últimos años, hace que la situación de discriminación y violación sistemática de los derechos humanos, en América Latina tienda a profundizar cada vez más las diferencias, ya existentes. Los últimos informes de la Secretaría Permanente para América Latina (SELA) respecto de la situación de

11. Raghavan Chakravathi. TME 85 Panorama Sombrio para el empleo en Europa, 2001 
la industria y el desempleo en América Latina ilustran lo anteriormente expresado.

En el año 1997 la industria manufacturera tenía un crecimiento de $6.3 \%$, en 1999 de $1.9 \%$ en el 2000 fue tan sólo un $1.5 \%$. Por supuesto esto repercutió en el desempleo urbano que venía experimentando una alza sostenida en la década pasada hasta alcanzar el año pasado el $8.6 \%$ de la fuerza laboral. ${ }^{12}$ El sector agrícola ha sido uno de los más azotados por las medidas proteccionistas de los países económicamente poderosos. La imposición de la cuota al banano, por los países de la Comunidad Europea afectó a miles de trabajadores, quienes de un día para otro se encontraron sin empleo y con sus familias desprotegidas. Al mismo tiempo el café ha venido mostrando una baja constante en los precios del mercado internacional. Esto es un pequeño ejemplo de muchos otros productos, a los cuales se les imponen no-sólo barreras arancelarias, si no también múltiples requisitos que finalmente conducen a lo mismo: la aplicación del libre comercio sólo para la conveniencia de los países desarrollados. Este aspecto se relaciona con un incremento en la actitud xenofóbica hacia los habitantes de los países latinoamericanos con quienes se utilizan términos despectivos tales como "los otros", "los intrusos", "los que me vienen a quitar trabajo", "los sudacas" etc. Así tenemos varios ejemplos de discriminación y xenofobia en diferentes países:

República Dominicana, se percibe el rechazo, desde el momento en que un turista le pregunta a un nativo, cual es la diferencia entre un haitiano y un dominicano, pues ambos conviven en una Isla relativamente pequeña de inmediato contestan: con cierta actitud despectiva que "ellos

12. El Nacional, Notas de prensa del SELA, Venezuela, 2 de abril de 2001. 
son la población negra, nosotros los descendientes de etnias indígenas -caribeñas y blancas; hasta en la pintura puedes notar la diferencia, nosotros tenemos una pintura menos primitivista".

En Chile, por ejemplo, llaman a los ecuatorianos y peruanos "cholos". En Perú a los ecuatorianos "los monos" e irónicamente los quiteños llaman de esta forma despectiva a los guayaquileños. Y en Argentina donde algunos se consideran "los más europeos" de América Latina, denominan a los inmigrantes paraguayos, bolivianos y a los mismos aymarás que se desplazan de su interior hacia Buenos Aires, los "cabecitas negras". En los Estados Unidos llaman a los mexicanos nacidos en Estados Unidos, "los chicanos". En Colombia las diferencias entre la costa y los del centro son muy marcadas y al referirse a los de la costa los del centro dicen despectivamente "los de la costa" que son menos trabajadores y toda su vida es un carnaval-Igual el costeño se refiere al del centro (Medellín y Bogotá) el "cachaco", que quiere decir el bien vestido el "entufado".

En Centroamérica siempre se han dado sobrenombres a los habitantes de los diferentes países, tales, "nicas" a los nicaragüenses "catracho" al hondureño, a los salvadoreños "los Guanacos" y al costarricense "ticos", pero conforme ha aumentado el flujo de migrantes, todas esos sobrenombres algunas veres adquieren un tono despectivo. Esto a su vez va acompañado de valoraciones o imágenes que se vienen cultivando desde tiempos ancestrales.

Se publicó hace poco en el boletín del Programa Ibero América: Unidad cultural en la diversidad, un artículo respecto a este tema, en el cual se expresa la preocupación por la creciente intolerancia entre los Latinoamericanos; en el que 
se ponía el ejemplo de Venezuela, país en el cual hace casi un año se retiró un texto escolar de circulación en que se calificaba como "irracional" la migración de colombianos, ecuatorianos, dominicanos, peruanos, cubanos y ciudadanos de otros países del Caribe a quienes se señaló como portadores de "costumbres violentas", afirmando entre otras cosas que "las mujeres venden su carne al mejor postor" para conseguir la nacionalidad Venezolana". ${ }^{13}$ Estas apreciaciones revelan algunos elementos interesantes:

a. La existencia de una acentuada migración intralatinoamericana.

b. Los comentarios despectivos que se tornan muy parecidos en Latinoamérica a los del resto del mundo. En Europa occidental se dan expresiones similares acerca de las personas que buscan una vida mejor, son mujeres y hombres de Europa del este o del África; o bien de las mujeres dominicanas en España. En Estados Unidos quizá difieran un poco las expresiones con respecto a los inmigrantes latinoamericanos, pero constantemente la imagen proyectada en el cine y la televisión es la de la empleada o empleado latino "torpe, ladrón o asesino".

\section{El caso costarricense. Situación económica y xeno- fobia}

Costa Rica no está libre de la situación señalada y es uno de los ejemplos más claros de un país del tercer mundo que debe hacer frente a una población de migrantes, que no pueden penetrar las fronteras de los países ricos y se ven

13. Hopenhayn Martín. Multiculturalismo Proactivo: Una reflexión para iniciar un debate, Barcelona. Boletín del Programa Ibero América: unidad cultural en la diversidad. Noviembre de 2000. 
forzados a buscar una vida mejor fuera de su país de origen. Costa Rica es escogida, por muchos inmigrantes, por ser una de las naciones del área que ofrece aún mayor estabilidad, política, económica y social, con un sistema de seguridad social donde por ley es obligatorio acoger en su seno a cualquier persona que resida en el país.

Sin embargo este país, también ha sufrido embates económicos y sociales muy fuertes especialmente en los últimos cuatro años. El grupo de Consejeros Económicos $\mathrm{Fi}$ nancieros S.A. (CEFSA), que le da seguimiento mensual a la realidad económica del país, ha expresado su preocupación en la prensa escrita, por el escenario socioeconómico actual $^{14}$.

El grupo CEFSA, afirma que en el 2000 el desempleo era de un $5.2 \%$ y que alcanzará a finales de este año $5.8 \%$ o sea 76.000 personas desempleadas, no tomándose aquí en cuenta el subempleo, del cual nadie puede asegurar una cifra cierta, pero que todos coinciden en que es muy alta.

En la sociedad costarricense se empieza a sentir el miedo a la crisis económica y consecuentemente al desempleo. Los Programas de Ajuste Estructural (PAE), han afectado a muchos sectores de la población entre ellos al sector agrícola; al negarle incentivos financieros o de otra índole, se condenó al agricultor a pasar serias dificultades, ya que como es de suponer, la mayoría de ellos, no conseguían dedicarse a otra cosa, pues por generaciones habían sido agricultores.

El palmito, es un caso típico de las políticas externas (PAE) aplicadas en los países del tercer mundo. Éste como

14. La Nación, Economía \& Negocios, San Jose, 6- julio del 2001. 
muchos otros productos, se dieron como fórmula alternativa a los agricultores para insertarse en el mercado internacional, el problema es que fue una receta igual para todos, por lo tanto hoy pasan una crisis los productores al tener que afrontar el excedente mundial, desequilibrio que se manifiesta con el despido hasta el momento de 380 personas. Así mismo la imposición de cuotas al banano por la Comunidad Europea, trajo consigo el desempleo entre 1994 . 2000 de 3.186 trabajadores.

En el área textil este año las maquiladoras han dejado 2000 personas sin empleo. La Banca estatal con la reestructuración entre el año 1994-2000 cesaron a 226 empleados y a finales del presente tendrían que prescindir de 371 personas más. En la Industria y el comercio se prevé una reducción de la planilla en un $16 \%$.

El ingreso del costarricense no ha crecido en dos años, mientras soporta una inflación y una depreciación a un ritmo mayor del colón con respecto al dólar.

Ante este panorama social, político y económico de inestabilidad, el costarricense se vuelve agresivo contra las personas foráneas. En el pasado, el comportamiento hacia la migración fue de gran aceptación. El país acogió a chinos, libaneses, polacos, africanos, chilenos, argentinos y centroamericanos. Estos inmigrantes no tuvieron problema de adaptación, por el contrario las personas extranjeras y sus hijos se sintieron como en "su tierra", y rápidamente llegaban a ocupar cargos elevados en sus labores.

No obstante, la xenofobia en la actualidad, se acrecienta día tras día. 
Desde hace aproximadamente cuatro años se escuchan frases despectivas, sobre todo con los nicaragüenses, a quienes culpan de usurpar sus trabajos, su lugar en el seguro social, de todo lo violento que ocurre etc. Y es quizá hasta hace unos meses atrás que se oyen expresiones que demuestran la inconformidad del costarricense contra los naturales de otros países, tal como Colombia y Cuba, las frases van de un tono muy hiriente a una simple queja, pero son emitidas con mucho más frecuencia, en los hogares, la escuela, el autobús y algunos medios informativos.

Ese tipo de expresiones utilizadas por los propios gobernantes y políticos, acentúan la animosidad hacia la población migratoria. El problema del odio o bien resentimiento entre personas que conviven en un mismo país, es que estos sentimientos no sólo se van incubando, en el grupo que se percibe desplazado de sus trabajos, si no también en el grupo que se siente maltratado y explotado, el resultado de continuar atizándolos puede resultar nefasto para ambos países.

Asimismo, se debe tomar en cuenta que los costarricenses tampoco están libres del inconveniente de emigrar del país por carestía. Un buen ejemplo es la difusión de la problemática que se da con pobladores de San Isidro de El General y de la zona de Los Santos y que ha llamado la atención por la cantidad de gente que emigra hacia Estados Unidos. Se han hecho muchos reportajes sobre este asunto y se conoce además que no son los únicos en el país. En Costa Rica se dan casos de familias separadas, porque el marido, la esposa, la madre, hermanos o hijos se ven obligados a dejar su hogar y luchar fuera de su tierra; esto se presenta generalmente, al no encontrar las condiciones de vida en el país, para que sus familiares puedan atender sus necesidades básicas, o bien lo que ellos consideran una vida digna. 


\section{Consideraciones finales}

En este momento se observa una tendencia al crecimiento y endurecimiento en las actitudes y los comportamientos xenofóbicos en el mundo. La crisis económica y social reforzada en la nueva dimensión economicista de la globalización impulsada por la sociedad capitalista, contribuye a este fenómeno.

La intolerancia se ha convertido en el quehacer político de grupos nacionalistas y ultranacionalistas que ven en la presencia de extranjeros y extraños -desde el punto de vista étnico-su infortunio. Este comportamiento es una especie de retorno a situaciones que se han dado en el pasado y que se alimentan esencialmente de la frustración y la incapacidad de dichos grupos para conseguir que sus necesidades puedan ser satisfechas por el mercado en la sociedad de consumo.

La educación, tanto desde el punto de vista formal como no formal, junto con los medios de comunicación que influyen de forma efectiva en la colectividad son herramientas fundamentales que han de asumir su responsabilidad en la atención de este peligroso fenómeno de nuestro tiempo.

La crisis económica fomentada desde las naciones industrializadas no puede ser el justificante esencial de las prácticas xenofóbicas y discriminatorias de la población. La crisis es un burdo pretexto para las prácticas de la intolerancia cualesquiera sean sus manifestaciones (políticas, étnicas, religiosas, culturales etc.)

La educación no formal cumple también una tarea importante en la formación de los jóvenes. Se debe estimular 
la participación y la formación de líderes juveniles así como la oportuna utilización del tiempo libre. El voluntariado en comunidades indígenas y fronterizas podría ser un instrumento importante hacia la tolerancia y la cooperación. Igualmente el trabajo con poblaciones migratorias y la atención de sus necesidades.

En síntesis la educación desempeña un papel fundamental en la construcción de la tolerancia, la civilidad y el respeto ajeno.

Tenemos que entender que el desplazamiento de personas de un lugar a otro, buscando mejores horizontes, no es un problema que se pueda resolver cerrando fronteras o fomentando el odio y desprecio hacia otras personas. La crisis económica, política y social, junto al fenómeno globalizante hace que el hambre derribe montañas, porque "el hambre y la miseria no tienen, ni respetan fronteras."

La sociedad debe asumir una responsabilidad ética con respecto a los grupos migratorios en lo que respecta a sus derechos. A fin de cuentas estas colectividades hacen importantes aportes al desarrollo económico y social de las naciones que les brindan su territorio. La explotación lejos de ser una solución se convierte en un delicado instrumento potencial de violencia. La miseria que estimula la sociedad de consumo y sus rígidos patrones económicos son en esencia más peligrosos para una nación en virtud de la injusticia y la marginalidad que generan. No tiene por tanto sentido asumir que "el extranjero o los de afuera" sean culpables por problemas que tienen raíz estructural. Hay sectores y actores de la sociedad que encuentran en estos grupos el "chivo expiatorio" perfecto de los males que ellos mismos originan. El doble discurso y la doble moral de elites de poder crean 
trampas sutiles a ignorantes e ingenuos. Con menuda frecuencia los medios masivos de comunicación se prestan también a esta tarea, de ahí que concienciar y educar sean herramientas básicas en esta lucha por parte de los grupos progresistas y de la sociedad civil organizada.

También parece importante reflexionar acerca de las acciones gubernamentales en torno a que se respeten las diferencias políticas, sociales y religiosas entre los habitantes de un país. Es trascendental señalar que los políticos y las políticas nacionales no deben enfatizar en esas diferencias porque podrían agudizarlas. Los grupos étnica, cultural o religiosamente diferentes, pueden insertarse en la nueva sociedad saltando las barreras que al inicio parecían infranqueables.

A fin de cuentas el respeto, la educación y la prudencia son la medicina para evitar profundizar más las divergencias entre las personas y por el contrario posibilitar la convivencia y la cooperación. Lo ideal es "humanizar al ser humano" y reconocer en la identidad humana el valor más importante. 


\section{BIBLIOGRAFÍA}

Bello Álvaro, Rangel Marta. "Etnicidad, Raza y Equidad en América Latina y el Caribe," CEPAL, doc.Lc/r, 1967, Agosto del 2001.

CEPAL. Panorama Social de América Latina. Chile, 1991.

Chomsky, Noam, Año 501 La Conquista Continúa. España, Edit. Libertarias Prodhufi, S.A, 1993.

Federación Internacional de Sociedades de la Cruz Roja. Los Retos del Desarrollo Humano. Edit. Absoluto. Costa Rica, 1993.

Hernández Omar, Ibarra Eugenia, Quesada Juan. Discriminación y Racismo, en la Historia Costarricense, San José Editorial Universidad de Costa Rica, 1993.

Hopenhayn, Martín. "Multiculturalismo Proactivo: Una Reflexión Para Iniciar un Debate," Barcelona. Boleún del Programa Ibero América: unidad cultural en la diversidad. Noviembre de 2000.

La Nación, Economía \& Negocios, San José, 6- Julio del 2001.

El Nacional, Notas de prensa del SELA Venezuela, 2 de Abril de 2001.

Moneta, Carlos. "Alternativas de Integración en el contexto de la globalización". Revista Nueva Sociedad. № 125, Venezuela 1993.

Neruda, Pablo. Confieso que he Vivido. Memorias. España. Edit. Seix Borral, S.A., 1979.

Odio, Elizabeth. Eliminación de todas las formas de intolerancia y discriminación fundadas en la religión o las convicciones. Nueva York, Publicación de la ONU, 1989.

PREALC. Ajuste Estructural y Deuda Social: un enfoque estructural, 1987.

Raghavan Chakravathi. TME 85 "Panorama Sombrío para el Empleo en Europa". 2001. 
Programa de Naciones Unidas para el Desarrollo. Informe de Desarrollo Humano, 1993-1999.

Perceval José María. Nacionalismos, xenofobia y racismo en la comunicación. Una perspectiva histórica. Barcelona, Edit. Paidos, 1995. 